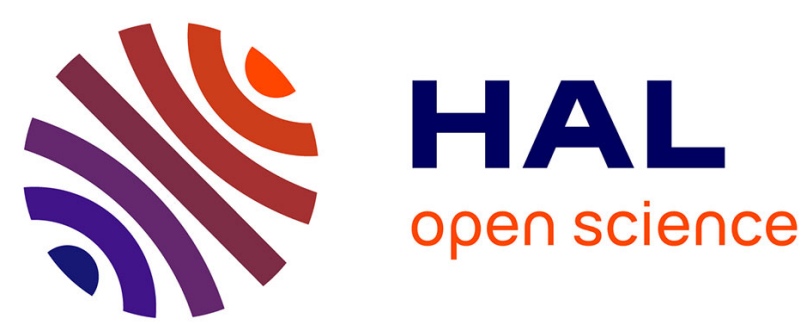

\title{
Allosteric Control of Naphthalene Diimide Encapsulation and Electron Transfer in Porphyrin Containers: Photophysical Studies and Molecular Dynamics Simulation
}

Laura Zanetti-polzi, Ryan Djemili, Stephanie Durot, Valérie Heitz, Isabella

Daidone, Barbara Ventura

\section{To cite this version:}

Laura Zanetti-polzi, Ryan Djemili, Stephanie Durot, Valérie Heitz, Isabella Daidone, et al.. Allosteric Control of Naphthalene Diimide Encapsulation and Electron Transfer in Porphyrin Containers: Photophysical Studies and Molecular Dynamics Simulation. Chemistry - A European Journal, 2020, 26 (72), pp.17514-17524. 10.1002/chem.202003151 . hal-03413681

\author{
HAL Id: hal-03413681 \\ https://hal.science/hal-03413681
}

Submitted on 3 Nov 2021

HAL is a multi-disciplinary open access archive for the deposit and dissemination of scientific research documents, whether they are published or not. The documents may come from teaching and research institutions in France or abroad, or from public or private research centers.
L'archive ouverte pluridisciplinaire HAL, est destinée au dépôt et à la diffusion de documents scientifiques de niveau recherche, publiés ou non, émanant des établissements d'enseignement et de recherche français ou étrangers, des laboratoires publics ou privés. 


\title{
Allosteric Control of Naphthalene Diimide Encapsulation and Electron Transfer in Porphyrin Containers: Photophysical Studies and Molecular Dynamics Simulation
}

\author{
Laura Zanetti-Polzi, ${ }^{[a]}$ Ryan Djemili, $^{[b]}$ Stéphanie Durot ${ }^{[b]}$ Valérie Heitz, ${ }^{*[b]}$ Isabella Daidone, ${ }^{*[c]}$ \\ and Barbara Ventura*[d]
}

Abstract: $\square$ Please provide academic title for each author - $\mathbf{0}$ The complexation processes of $\mathrm{N}, \mathrm{N}^{\prime}$-dibutyl-1,4,5,8naphthalene diimide (NDI) into two types of $\pi$-electron-rich molecular containers consisting of two $\mathrm{Zn}$ "-porphyrins connected by four flexible linkers of two different lengths, were characterized by means of absorption and emission spectroscopies and molecular dynamics simulation. Notably, the addition of NDI leads to a strong quenching of the fluorescence of both cages only when they are in an open conformation suitable for guest encapsulation, a situation triggered by silver(l) ions binding to the lateral triazoles. Molecular dynamics simulations confirm the fast binding of NDI, likely assisted by NDI-silver(I) interactions. Upon NDI complexation, the two porphyrin macrocycles get closer, with an optimized face to face orientation, suggesting an induced-fit mechanism through $\pi-\pi$ interactions with the NDI aromatic cycle. Ultrafast transient absorption experiments allowed to identify the process of quenching of the Zn-porphyrin fluorescence as an efficient photoinduced electron transfer reaction between the cage porphyrin and the included NDI guest. The process occurs on fast and ultrafast time scales in the two complexes ( $1.5 \mathrm{ps}$ and $\leq 300 \mathrm{fs}$ ) leading to a shortlived charge separated state (charge recombination lifetimes in the order of 30-40 ps). The combined computational and experimental approach used here is able to furnish a reliable model of the NDI-cage complexation mechanism and of the corresponding electron transfer reaction, attesting the allosteric control of both processes by the silver(I) ions.

\section{Introduction}

Reversible encapsulation of guest molecules inside the cavity of three-dimensional structures is a phenomenon of great interest in supramolecular chemistry. It enables the guest to be isolated from the bulk medium and to establish new interac-

\section{[a] L. Zanetti-Polzi}

CNR Institute of Nanoscience

Via Campi 213/A, 41125 Modena(Italy)

[b] R. Djemili, S. Durot, V. Heitz

Laboratoire de Synthèse des Assemblages Moléculaires Multifonctionnels Institut de Chimie de Strasbourg, CNRS/UMR 7177

Université de Strasbourg

4, rue Blaise Pascal, 67000 Strasbourg (France)

E-mail:v.heitz@unistra.fr

[c] I. Daidone

Department of Physical and Chemical Sciences

University of L'Aquila

via Vetoio (Coppito 1), 67010 L'Aquila(Italy)

E-mail: isabella.daidone@univaq.it

[d] B. Ventura

Istituto per la Sintesi Organica e la Fotoreattività (ISOF)

Consiglio Nazionale delle Ricerche (CNR)

Via P. Gobetti 101, 40129 Bologna (Italy)

E-mail: barbara.ventura@isof.cnr.it

$\square$ Supporting information and the ORCID identification number(s) for the au-

(iD thor(s) of this article can be found under:

https://doi.org/10.1002/chem.202003151. tions with its host which affect their mutual physical and chemical properties. ${ }^{[1]}$ The new properties that emerge from this close association have opened the way to applications in many areas of chemical, biological and material sciences. Encapsulation is often a critical step to access to more complex processes where the guest plays the role of the substrate or the catalyst in chemical transformations, the active drug in drug-delivery systems or the functional molecular unit in selfhealing materials. ${ }^{[2]}$ Therefore, the stability and lability of the inclusion complex in a given environment has to be controlled by a fine electronic and geometrical match between the host and the guest which is not easily transposable from one environment to another one. ${ }^{[3]}$ Interestingly, guest complexation can also be controlled with external stimuli, such as photons, ${ }^{[4]}$ electrons $^{[5]}$ or chemical entities, ${ }^{[6]}$ that interact with specific sites of the host, remote from the binding sites of the guest and induce large and reversible modifications of the host structure. Such control is reminiscent of the allosteric control used by many biological systems such as proteins, enzymes and molecular machines. ${ }^{[7]}$ Inclusion complexes are also well suited for achieving efficient photoinduced electron transfer, a key process in natural photosynthesis. The primary photoinduced electron transfer steps occurring in the Photosystem II involve a photoexcited dimer belonging to the family of porphyrin derivatives and a series of electron acceptors all maintained in a specific spatial organization through non covalent 
interactions in a protein host. ${ }^{[8]}$ Notably, the last electron acceptor, a quinone, once doubly reduced and protonated loses its affinity for its binding pocket, leaves the protein and is replaced by a fresh quinone. ${ }^{[9]}$ The modified affinity of the quinone in its reduced and protonated states for its host and its reversible binding is at the origin of the developed protonmotive force and the subsequently generated chemical energy. Regarding the importance of these processes, photoinduced electron transfer between porphyrins and electron acceptors in non-covalent hybrids has been investigated in different biomimetic inclusion complexes, ${ }^{[10]}$ in mechanically linked structures in the context of molecular machines ${ }^{[11]}$ and supramolecular optoelectronic devices. ${ }^{[12]}$ Nevertheless, limited examples have reported on an allosteric control of photoinduced electron transfer. ${ }^{[10 c, 11 a, b, i]}$

In this vein, we were interested in studying the inclusion complex of $\mathrm{N}, \mathrm{N}^{\prime}$-dibutyl-1,4,5,8-naphthalene diimide (NDI) into $\pi$-electron-rich hosts possibly giving rise to photoinduced electron transfer processes. In particular, we studied the inclusion of NDI in molecular cages, that we call $\mathbf{1}$ and 2, consisting of two $\mathrm{Zn}$ "-porphyrins connected by four flexible linkers of different lengths, endowed with triazole binding sites (Figure 1). 1,4,5,8-Naphthalene diimide, as a versatile aromatic $\pi$-acceptor, was previously combined with various $\pi$-rich donors including porphyrins in the context of supramolecular host-guest systems. ${ }^{[13]}$ Previous studies performed with the molecular container 1 endowed with the "short" linkers revealed that it behaves as an allosteric receptor, able to encapsulate NDI only once the container was in an open form, obtained upon sil$\operatorname{ver}(\mathrm{I})$ ions binding to the lateral triazoles. ${ }^{[14]}$ Here, combined spectroscopic and computational studies are reported to shed light on the binding affinity of NDI, on its dynamic encapsulation induced by the opening of containers $\mathbf{1}$ and $\mathbf{2}$ upon silver(l) ions binding and on the photoinduced electron transfer process taking place within the assembly. The structural char- acterization of the complexation process is obtained by multiple, explicit solvent, molecular dynamics (MD) simulations and the photophysics of the inclusion complexes is investigated by means of ultrafast transient absorption spectroscopy. Binding of silver(I) ions to the lateral linkers is shown to be the event that controls and drives NDI inclusion and thus the occurrence of the photoinduced electron transfer reaction between the $\mathrm{Zn}$-porphyrins of the host and the NDI guest.

\section{Results and Discussion}

\section{Photophysical characterization and evaluation of guest binding in diluted solutions}

The photophysical properties of cages 1 and 2 and of their sil$\operatorname{ver}(\mathrm{l})$ complexes $\left[\mathrm{Ag}_{4}(\mathbf{1})\right](\mathrm{OTf})_{4}$ and $\left[\mathrm{Ag}_{4}(\mathbf{2})\right](\mathrm{OTf})_{4}$ in $\mathrm{CH}_{2} \mathrm{Cl}_{2} /$ $\mathrm{MeOH}(90: 10)$, a solvent mixture that could ensure good solubility of the porphyrin cages and of the silver salt Ag(OTf), were previously reported. ${ }^{[15]} \mathrm{A}$ complete characterization of the absorption and emission properties of the guest NDI in the same solvent mixture has been performed, and the results are summarized in the ESI (Figure S1 and Table S1). In diluted solutions $\left(C \leq 10^{-6} \mathrm{M}\right)$ NDI shows the typical absorption and emission features of the monomeric species: a structured absorption in the UV region, with $\varepsilon_{380 \mathrm{~nm}}=2.62 \times 10^{4} \mathrm{M}^{-1} \mathrm{~cm}^{-1}$, and a weak fluorescence $\left(\phi \mathrm{f}_{\mathrm{l}}=0.0017\right)$ with a vibronic structure mirroring the absorption spectrum. ${ }^{[16]}$ Upon increasing the concentration, additional absorption features in the range 450$600 \mathrm{~nm}$ and a broad emission band peaking at $566 \mathrm{~nm}$ appear; a similar red-shifted emission has been reported for excimers or excited dimers of naphthalene diimides in concentrated solutions or packed structures. ${ }^{[16 a, 17]}$ In our system this secondary emission could be clearly characterized in concentrated solutions $\left(10^{-4} \mathrm{M}\right.$ onwards) where the excitation spectrum collected at $600 \mathrm{~nm}$ matches the absorption bands present in the $450-$

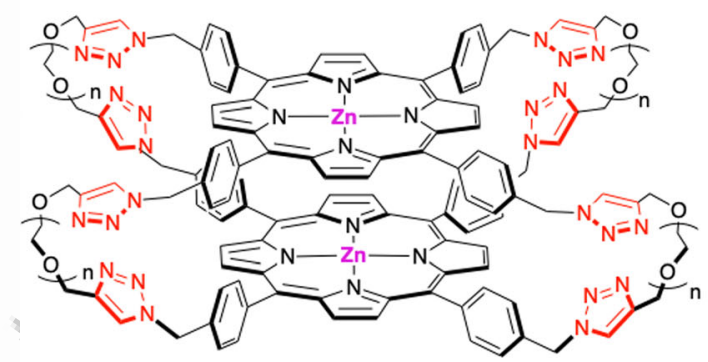

1: $\mathrm{n}=1$

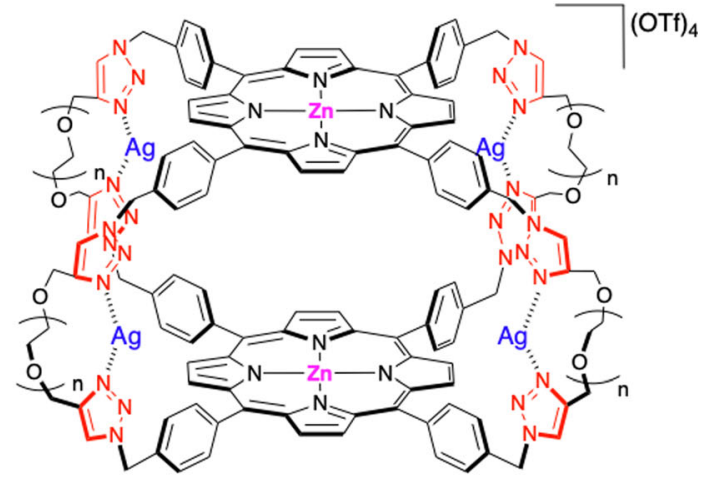

$\left[\mathrm{Ag}_{4}(1)\right](\mathrm{OTf})_{4}: \mathrm{n}=1$

$\left[\mathrm{Ag}_{4}(2)\right](\mathrm{OTf})_{4}: \mathrm{n}=2$

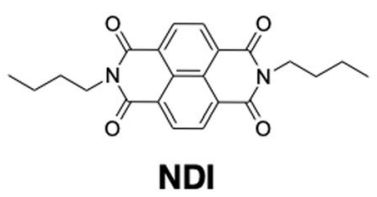

Figure 1. Chemical structures of the hosts 1 and 2, their silver(I) complexes and of the NDI guest. 
$600 \mathrm{~nm}$ region (Figure S1), evidencing that it arises from a ground state dimer or higher order aggregate (indicated generally as $\mathbf{N D I}_{\mathbf{n}}$ ).

Moving towards the analysis of the binding between the bis-porphyrinic cages 1 and $\mathbf{2}$ and the NDI guest, we examined the photophysical properties of the cages, in their closed conformation, once treated with an excess of NDI. Absorption and emission spectra registered for mixtures of cage (ca. $2 \times 10^{-7} \mathrm{M}$ ) and NDI (ca. $1 \times 10^{-4} \mathrm{M}, \geq 500$ equiv) are reported in Figures S2 and S3 for cages 1 and 2, respectively. It is evident that there are no changes in the absorption features of the cages in the mixtures, while a slight reduction of emission intensity, that is, $3 \%$ for $\mathbf{1}$ and $7 \%$ for $\mathbf{2}$, is observed. The latter is paralleled by measured excited state lifetimes of $1.64 \mathrm{~ns}$ (vs. $1.71 \mathrm{~ns}$ ) and $1.54 \mathrm{~ns}$ (vs. $1.64 \mathrm{~ns}$ ) for $\mathbf{1}$ and $\mathbf{2}$ in the mixtures (vs. cage alone), ${ }^{[15]}$ respectively. Though small, this quenching can be considered as a result of a bimolecular interaction between the cage and NDI molecules, and reaction rate constants of $2.7 \times 10^{11} \mathrm{M}^{-1} \mathrm{~s}^{-1}$ for 1 and $4.4 \times 10^{11} \mathrm{M}^{-1} \mathrm{~s}^{-1}$ for 2 could be derived, values one order of magnitude higher than the diffusion controlled rate constant $\left(k_{\text {diff, } \mathrm{CH}_{2} \mathrm{Cl}_{2}}=1.5 \times 10^{10} \mathrm{M}^{-1} \mathrm{~s}^{-1}\right.$ at $293 \mathrm{~K}) .{ }^{[18]}$ This outcome seems to indicate that short-lived encounter complexes, where the cages interact with external NDI molecules, are operative in the reduction of the porphyrins fluorescence for less than $10 \%$. Formation of such encounter complexes is also predicted by molecular dynamics simulations (see below).

The process of inclusion of the guest NDI inside the two zinc-porphyrin cages, once their cavity is enlarged by the binding of $\mathrm{Ag}^{+}$to the peripheral triazole ligands, has been investigated in diluted solutions by means of absorption and fluorescence spectroscopy. Prior to the addition of NDI, the Ag' complexes $\left[\mathrm{Ag}_{4}(\mathbf{1})\right](\mathrm{OTf})_{4}$ and $\left[\mathrm{Ag}_{4}(\mathbf{2})\right](\mathrm{OTf})_{4}$ were prepared by adding $\mathrm{Ag}(\mathrm{OTf})$ to $\mathrm{CH}_{2} \mathrm{Cl}_{2} / \mathrm{MeOH}$ (90:10) solutions of the cages, as previously described. ${ }^{[15,19]}$

Addition of NDI (0-463 equivalents) to a solution of $\left[\mathrm{Ag}_{4}(\mathbf{1})\right](\mathrm{OTf})_{4}\left(1.8 \times 10^{-7} \mathrm{M}\right)$ leads to a decrease in absorption of the Soret band, as shown in Figure $2 \mathrm{~A}$, testifying an electronic interaction between the $\mathrm{Zn}$-porphyrins of the cage and the guest. Fluorescence titration experiments were performed upon excitation at $434 \mathrm{~nm}$, isosbestic of the absorption spectra. In order to clearly analyse the trend of the emission intensity of the open cage within the titration, each emission spectrum has been subtracted by the contribution of $\mathrm{NDI}_{n}$, collected from a "blank" solution of NDI prepared at the same concentration as in each titration point (see Figure S4). This was made necessary since, even if the absorbance of the formed $\mathrm{NDI}_{\mathrm{n}}$ at $434 \mathrm{~nm}$ is very low $(<0.0010)$ in the range $0-8.5 \times$ $10^{-5} \mathrm{M}$ of NDI used for the titration, its emission is intense enough ( $\phi=0.15$, Table 51 ) to show up and sum to the fluorescence of the porphyrin cage (Figure S4). The emission spectra thus derived $(\Delta /(\lambda))$, reported in Figure $2 \mathrm{~B}$, show a decrease of the emission intensity of $\left[\operatorname{Ag}_{4}(\mathbf{1})\right]^{4+}$ upon addition of NDI. The observed changes clearly indicate the formation of an inclusion complex between the $\left[\mathrm{Ag}_{4}(\mathbf{1})\right]^{4+}$ open cage and NDI.

In order to derive the association constant for the process of NDI complexation, emission titration data have been analysed both by Reactlab Equilibria ${ }^{[20]}$ and Hypspec ${ }^{[21]}$ software (the best fittings were obtained using a 1:1 complexation model) and by fitting the data with a specific equation related to a 1:1 complex formation (see Equation (1) in the Experimental Section). A couple of examples of fittings of the emission data treated with Hypspec software are reported in Figure S5. An average association constant of $(4150 \pm 39) \mathrm{M}^{-1}$ is derived for the formation of the NDI@ $\left[\mathrm{Ag}_{4}(\mathbf{1})\right]^{4+}$ complex. It can be noticed that a lower value of $K_{\mathrm{a}}=(95 \pm 20) \mathrm{M}^{-1}$ was found for the formation of $\mathrm{NDI}\left[\mathrm{Ag}_{4}(\mathbf{1})\right]^{4+}$ in $\mathrm{CD}_{2} \mathrm{Cl}_{2}$, through ${ }^{1} \mathrm{H}$ NMR titration of $\left[\mathrm{Ag}_{4}(\mathbf{1})\right](\mathrm{BArF})_{4}$ with NDI. ${ }^{[14]}$ Some considerations can be made to explain the discrepancy of the two constants. The present value might be overestimated by the contribution given by bimolecular external quenching occurring when the NDI concentration increases. Moreover, absorption and emission titrations were conducted in a low complex concentration range (about $20-30 \%$ of formed complex at the end of the titration) due to the necessity to work in optical conditions and the fittings were limited to an initial close to linear dependence range (Figure S5). Also, the formation of $\mathrm{NDI}_{n}$ species could contribute to lower the real monomeric NDI concentration compared to the expected one, affecting the mathematical treatment. The latter should have only a slight influence, by
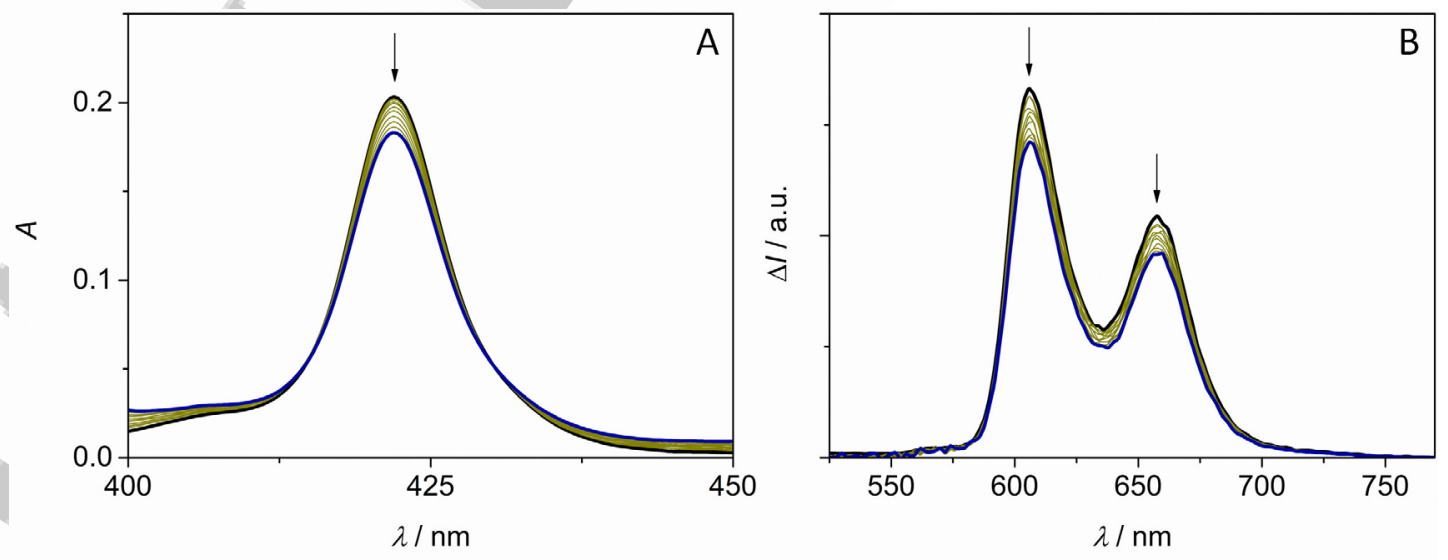

Figure 2. A) Absorption spectra of $\mathrm{CH}_{2} \mathrm{Cl}_{2} / \mathrm{MeOH}(9: 1)$ solutions of cage $\left[\mathrm{Ag}_{4}(\mathbf{1})\right]^{4+}\left(1.8 \times 10^{-7} \mathrm{M}\right)$ with increasing amounts of $\mathrm{NDI}(0-463$ equiv). B) Differential (see text) emission spectra of the same solutions as in $A$; excitation at $434 \mathrm{~nm}$. 
considering self-association constants of $1-2 \mathrm{M}^{-1}$ reported for a naphthalene diimide in solvents of various polarity. ${ }^{[22]}$ Finally, one should consider that both the solvent and the complex counterions were different in this study with respect to the previous one, ${ }^{[14]}$ plausibly leading to a different value of the association constant. A solvophobic effect can, in fact, be operative in the present case where the more polar solvent mixture favours NDI encapsulation. ${ }^{[23]}$

The same titration experiments were performed with $\left[\mathrm{Ag}_{4}(\mathbf{2})\right](\mathrm{OTf})_{4}$. Absorption and emission changes observed for a $2.0 \times 10^{-7} \mathrm{M}$ solution of $\left[\mathrm{Ag}_{4}(2)\right]^{4+}$ titrated with $\mathrm{NDI}$ in the range $0-463$ equivalents, are reported in Figure $\mathrm{S} 6$. The emission trend was followed upon excitation at $425 \mathrm{~nm}$, isosbestic of the absorption titration, and by correcting the spectra for the emission of $\mathbf{N D I}_{n}$ (see Figure S7), as in the previous case. The observed changes in both absorption and emission of $\left[\mathrm{Ag}_{4}(\mathbf{2})\right]^{4+}$ are similar to those observed for $\left[\operatorname{Ag}_{4}(\mathbf{1})\right]^{4+}$, pointing to the same type of complexation. The titration data have been mathematically analyzed by means of Reactlab Equilibria and Hypspec software, with a 1:1 complexation model, and by using Equation (1) in the Experimental section. Examples of trends of emission intensities at selected wavelengths, analysed with Hypspec software, are reported in Figure S8. The derived average association constant for the formation of the $\mathrm{NDI} @\left[\mathrm{Ag}_{4}(2)\right]^{4+}$ complex is $\left(4018 \pm 47 \mathrm{M}^{-1}\right)$. Also in this case, we cannot exclude an overestimation of the association constant for the reasons discussed above.

Overall, the spectral changes observed in the absorption titrations and the stronger quenching observed in the fluorescence experiments once the cages $\mathbf{1}$ and $\mathbf{2}$ are open with sil-

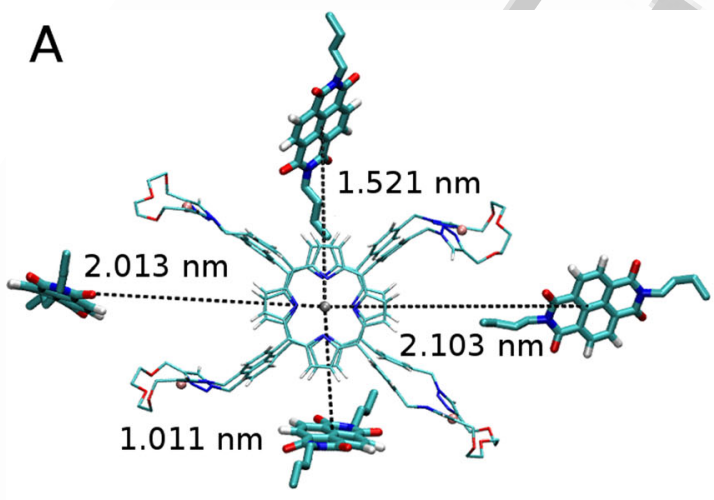

B

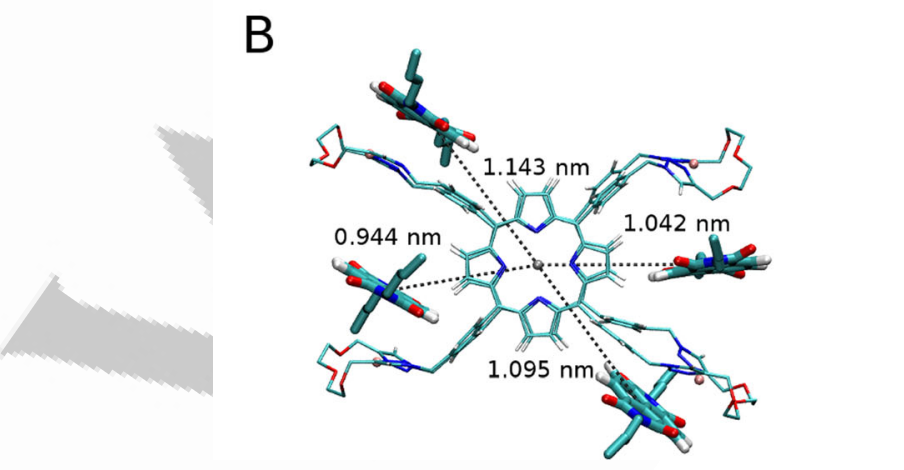

ver(l), endorse an assembly process where the NDI guest is steadily included inside the cavity of the cage. In order to gain precious information on type and geometry of the host/guest interactions at the basis of the observed phenomena, detailed computational investigation has been performed (see below).

\section{Computational results}

Two 100-ns long MD simulations of silver(I)-complexed cage $\mathbf{2}$, $\left[\mathrm{Ag}_{4}(2)\right]^{4+}$, in the presence of four NDI molecules are performed in $\mathrm{CH}_{2} \mathrm{Cl}_{2} / \mathrm{MeOH}$ (90:10) at $300 \mathrm{~K}$ reproducing the experimental conditions (see the Methods section for a justification of this choice). Two starting configurations for the four NDI molecules are chosen. In the first one, the four NDI molecules are placed at a distance from the center of mass of the two Zn-porphyrins varying from $\approx 1 \mathrm{~nm}$ to $\approx 2 \mathrm{~nm}$ and with different orientations between the NDI plane and the porphyrin planes (see Figure $3 \mathrm{~A}$ ).

In this configuration the NDI molecules are not forced to interact with the $\left[\mathrm{Ag}_{4}(2)\right]^{4+}$ cage in a specific way. However, at such distances both the NDI molecules and the cage do not behave as freely diffusing molecules in solution, as an interaction among them is already present. ${ }^{[24]}$ Thus, this choice allows both to follow an unbiased interaction among the five molecules and to speed up a possible complexation between the NDI molecules and the cage, bypassing the time-limiting step of the purely diffusive encountering of the solvated molecules. The analysis of the MD simulation starting from this configuration highlighted the presence of transient interactions between the NDI molecules and the $\mathrm{Ag}^{+}$ions coordinated to the

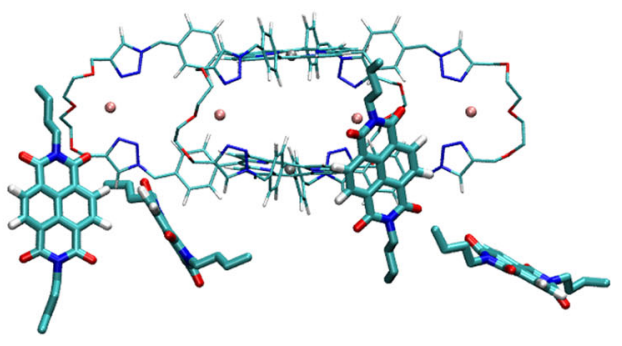

Figure 3. Top (left) and side (right) view of the first (A) and second (B) starting configurations for the silver(I)-complexed cage 2 and the four NDI molecules.

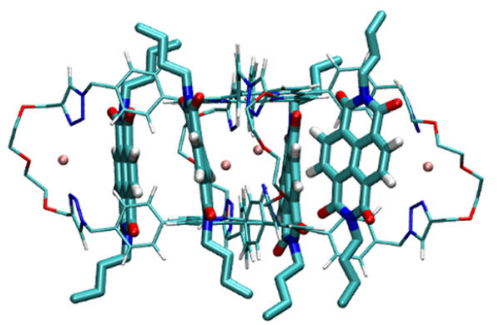


linkers (see below). Thus, a second starting configuration is tested in which the NDI molecules are placed perpendicularly to the two porphyrin planes in-between the four linkers (i.e., with each NDI molecule at a distance of $\approx 0.5 \mathrm{~nm}$ from a sil$\operatorname{ver}(\mathrm{I})$ ion of one linker) with an average distance between the center of mass of the NDI and the center of mass of the two $\mathrm{Zn}$ atoms of $\approx 1 \mathrm{~nm}$ (see Figure $3 \mathrm{~B}$ ). In this second starting configuration the interaction between each NDI molecule and a silver(I) ion is favored, in order to investigate the possible role of such interaction in the formation of the NDI@ $\left[\mathrm{Ag}_{4}(2)\right]^{4+}$ complex.

In both simulations, one NDI molecule spontaneously enters the cage after a few nanoseconds forming a complex that remains stable for the rest of the simulation. In the MD simulation starting from the first configuration, an NDI molecule (hereafter called NDI2) enters the cage after $\approx 6 \mathrm{~ns}$ (see Figure $4 \mathrm{~A}$ ). After an initial diffusion (lasting $\approx 2.5 \mathrm{~ns}$ ) during which the distance between the cage and the NDI2 centers of mass
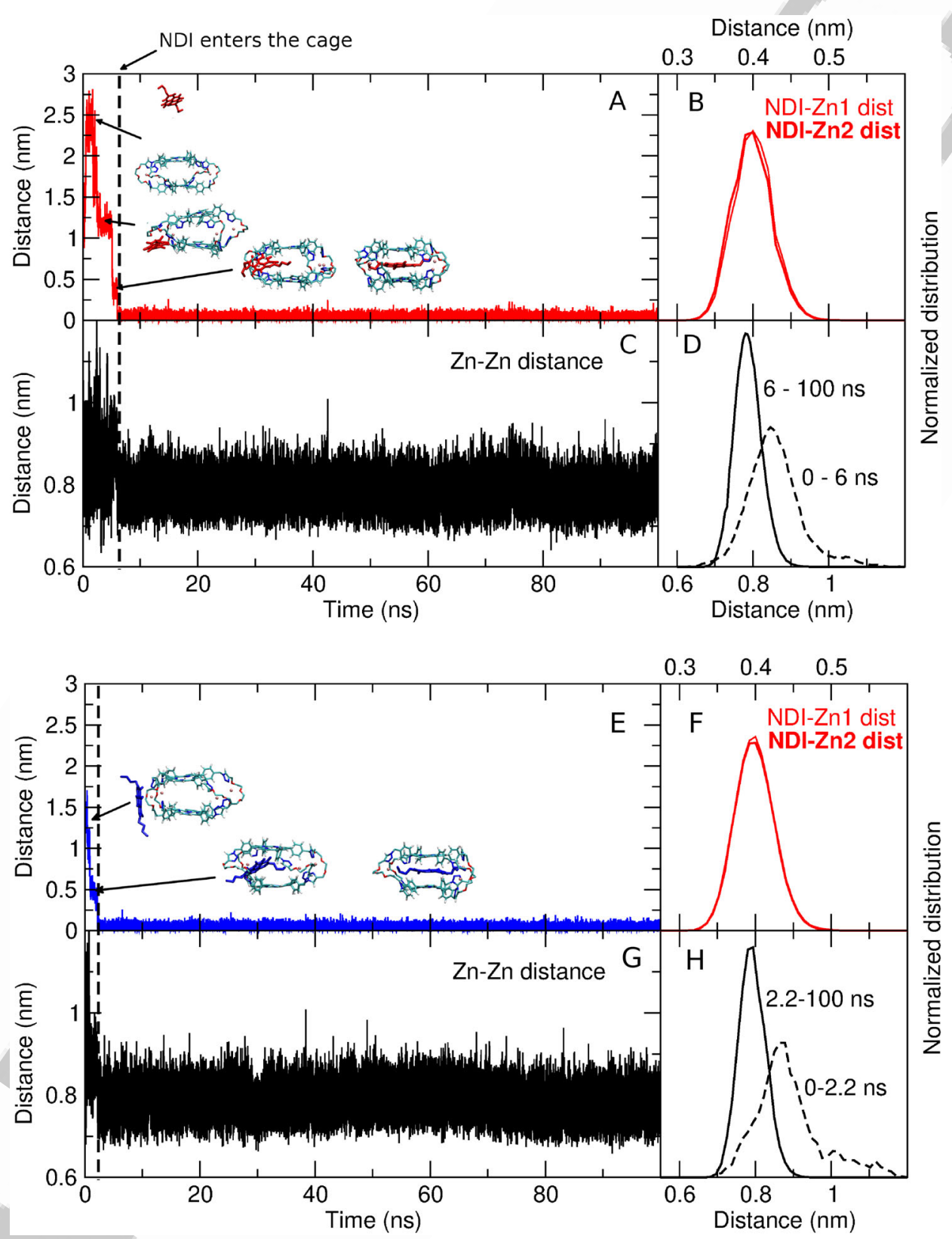

Figure 4. A, E) Time evolution of the distance between the center of mass of an NDI molecule (NDI2 in the MD starting from the first configuration, panel A, and NDI4 in the MD starting from the second configuration, panel E) and the center of mass of the two Zn-porphyrins. The vertical dashed line highlights the time at which the NDI molecules enter the cage ( $\approx 6 \mathrm{~ns}$ and $\approx 2.2 \mathrm{~ns}$ for the first and second starting configurations, respectively). Representative structures of the relative position of the NDI molecules and the $\left[\mathrm{Ag}_{4}(\mathbf{2})\right]^{4+}$ cage are reported. B,F) Normalized distribution of the distance between the center of mass of NDI2/NDI4 and each of the two $\mathrm{Zn}$ atoms of the porphyrin rings after NDI enters the $\left[\mathrm{Ag}_{4}(2)\right]^{4+}$ cage $(6-100 \mathrm{~ns}$ and $2.2-100 \mathrm{~ns}$ for the first (B) and second (F) starting configurations, respectively). $C, G$ ) Time evolution of the distance between the two $\mathrm{Zn}$ atoms of the porphyrin rings. $\mathrm{D}, \mathrm{H}$ ) Normalized distribution of the distance between the two $\mathrm{Zn}$ atoms of the porphyrin rings before (0-6 ns and 0-2.2 ns for the first (D), and second (H), starting configuration, respective-

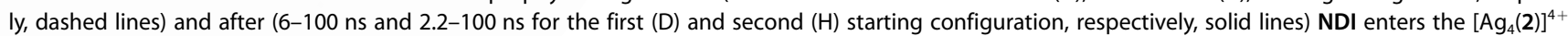
cage. 
reaches $\approx 2.7 \mathrm{~nm}, \mathrm{NDI} 2$ approaches the cage, interacting with the $\mathrm{Ag}^{+}$ion of one of the linkers. During the $\approx 2.5 \mathrm{~ns}$ in which NDI2 interacts with the silver(I) ion, the distance between the $\mathrm{Ag}^{+}$ion and the center of mass of the NDI molecule is maintained at $\approx 0.5 \mathrm{~nm}$, suggesting the presence of a cation- $\pi$ interaction between the silver $(\mathrm{I})$ ion and the NDI. Then, NDI2 starts entering the cage. After further $\approx 1$ ns the entering process is completed and NDI2 is in the center of the cage, essentially parallel to the porphyrin planes (see below). In the MD simulation starting from the second configuration, an NDI molecule (NDI4) enters the cage after $\approx 2.2$ ns (see Figure $4 \mathrm{E}$ ). In the first $\approx 1$ ns of the simulation NDI4 interacts with the sil$\operatorname{ver}(\mathrm{l})$ ion, with an average distance between the $\mathrm{Ag}^{+}$ion and the center of mass of NDI4 of is $\approx 0.55 \mathrm{~nm}$, analogously to what observed in the MD simulation starting from the first configuration.

The results of both MD simulations suggest that the interaction with the $\mathrm{Ag}^{+}$ion might be relevant for the complexation between the NDI and the $\left[\mathrm{Ag}_{4}(\mathbf{2})\right]^{4+}$ cage, maintaining the NDI molecule between the $\mathrm{Zn}$-porphyrin planes until the proper orientation to enter the cage cavity is found.

It can be noted from Figure $4 \mathrm{~B}$ and $\mathrm{F}$ that in the stable complex, the NDI molecule is in the center of the cage. In fact, the normalized distributions of the distance between the center of mass of NDI2/NDI4 and each of the two $\mathrm{Zn}$ " metal centers of the porphyrin rings are essentially indistinguishable and peaked at the same distance $(0.39 \mathrm{~nm})$. Such a distance is only slightly higher than a typical $\pi-\pi$ interaction distance $(0.35 \mathrm{~nm}),{ }^{[23,25]}$ suggesting a suboptimal electronic interaction between the NDI and the porphyrin rings, in agreement with the experimental binding constant measured by UV-visible and NMR titrations. ${ }^{[14]}$

In our previous work, ${ }^{[15]}$ MD simulations showed that in the complexed $\left[\mathrm{Ag}_{4}(2)\right]^{4+}$ cage the two $\mathrm{Zn}$-porphyrins are highly rigid and adopt, in solution, a cofacial position with an average distance between the $\mathrm{Zn}$ " centers of mass of $\approx 0.85 \mathrm{~nm}$. Upon complexation with the NDI molecule a reduction of the distance between the two porphyrin macrocycles is observed (see Figure 4C, D, G, and H). In fact, the distance between the two $\mathrm{Zn}$ " metal ions of the porphyrins decreases from $\approx 0.85 \mathrm{~nm}$ to $\approx 0.78 \mathrm{~nm}$ upon complexation, suggesting a sort of induced-fit mechanism.

The NDI-cage complex was further investigated by analyzing the relative orientation of the three planes (i.e., the two porphyrin planes and the NDI plane). In what follows, the results obtained from the MD simulations starting from the two different conformations, being analogous, are reported together. To assess the effect of the formation of the complex on the geometry of the $\left[\mathrm{Ag}_{4}(2)\right]^{4+}$ cage, the angles between each of the $\mathrm{Zn}$-porphyrin plane and the vector connecting the two centers of mass $\left(\theta_{1}, \theta_{2}\right)$ are analyzed before and after the formation of the complex (see Figure $5 \mathrm{~A}$ ). It can be observed that, upon complexation with the NDI molecule, the porphyrins of the $\left[\mathrm{Ag}_{4}(2)\right]^{4+}$ cage adopt a more cofacial conformation, $82^{\circ}$ being the most populated angle with a sharper distribution when the NDI molecule is located inside the cage and $75^{\circ}$ being the most populated one and with a broader distribution, when the NDI molecule is outside the cage. The two porphyrin planes are also mainly parallel, as the bi-dimensional distribution of $\theta_{1}$ and $\theta_{2}$ shows a strong linear correlation (see Figure S9A). The $75^{\circ}$ value found for $\theta_{1}$ and $\theta_{2}$ when the NDI is outside the cage is in agreement with what was observed during a previously performed $100 \mathrm{~ns}$-long MD simulation of the same cage in the absence of NDI molecules, in which the most populated angle was $78^{\circ} \cdot{ }^{[15]}$

The angles between the NDI plane and the vectors connecting the centers of mass of each porphyrin plane and of the NDI molecule $\left(\phi_{1}\right.$ and $\left.\gamma_{1}\right)$, as well as the angles between the $Z n$-porphyrin planes and the same vectors $\left(\phi_{2}\right.$ and $\left.\gamma_{2}\right)$ were also analyzed. Their normalized distribution (Figure $5 \mathrm{~B}$ ) shows that the NDI plane is also almost cofacial to the two porphyrin planes. It can be noted that the most populated values of $\phi_{1}$ and $\gamma_{1}$ are slightly lower than the ones of $\phi_{2}$ and $\gamma_{2}\left(78^{\circ} \mathrm{vs}\right.$. $82^{\circ}$ ), but such a difference is negligible and the three planes are essentially parallel and cofacial.
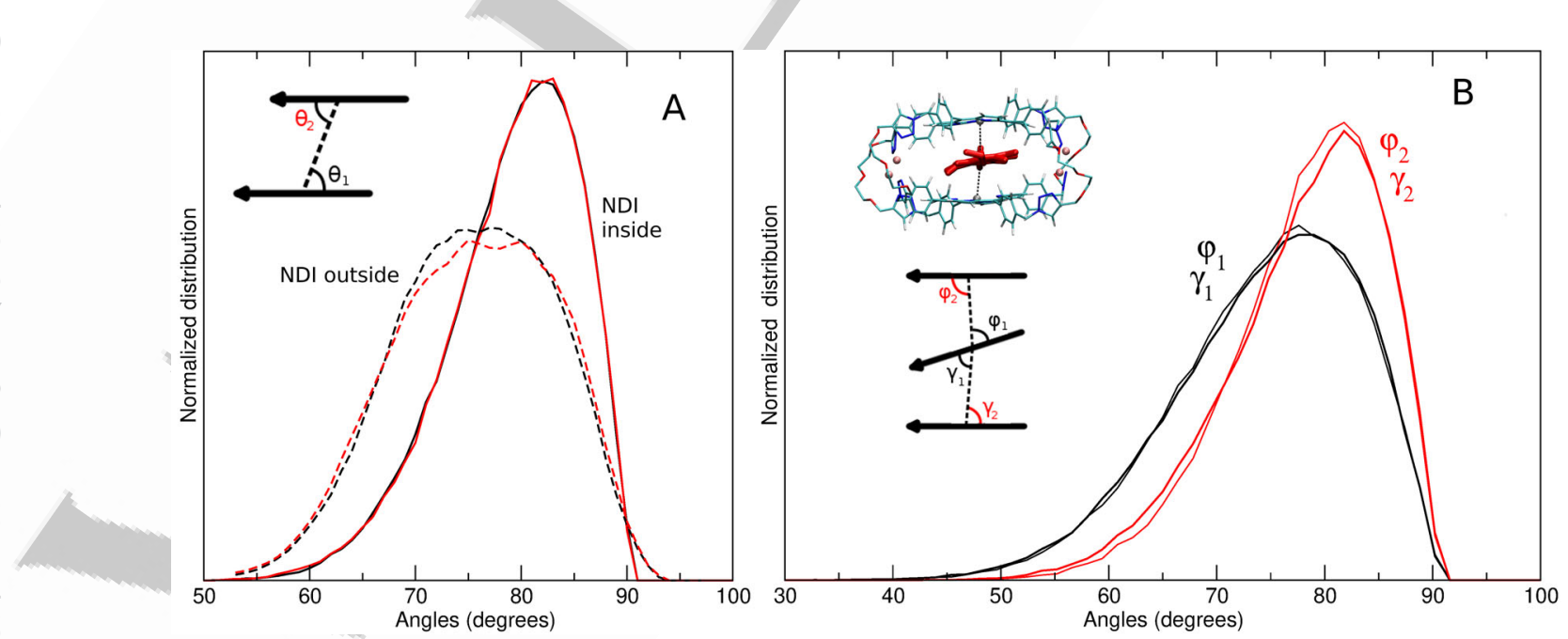

Figure 5. A) Normalized distribution of $\theta_{1}$ and $\theta_{2}$ before (dashed line) and after (solid line) the complexation of the [Ag $\left.{ }_{4}(2)\right]^{4+}$ cage with the $\mathbf{N D I}$ molecule. B) Normalized distribution of $\phi_{1}$ and $\phi_{2}, \gamma_{1}$ and $\gamma_{2}$ when the NDI-cage complex is formed. 
The angle defining the rotation of the porphyrin planes one with respect to the other $(\beta)$ and the angles between the NDI plane and each porphyrin plane $\left(\beta_{1}\right.$ and $\left.\beta_{2}\right)$ were also analyzed along the MD simulations (see Figure $\mathrm{S10}$ ). In agreement with what previously found ${ }^{[15]}$ such angles display small variations along the simulation, the most populated $\beta$ angle being $26^{\circ}$ and the most populated $\beta_{1}$ and $\beta_{2}$ angles being $14^{\circ}$ (Figure S10).

The behavior of the three NDI molecules that are not complexed with the $\left[\mathrm{Ag}_{4}(2)\right]^{4+}$ cage was also analyzed during the MD simulation by calculating the distance between the center of mass of each NDI molecule and the center of mass of the $\left[\mathrm{Ag}_{4}(2)\right]^{4+}$ cage. The results obtained from the MD simulation starting from the first configuration are reported in Figure 6 and the ones obtained from the MD simulation starting from the second configuration are reported in Figure S11. It can be observed in the figures that the three NDI molecules that remain outside the cage interact with it by forming short-lived complexes (i.e. encounter complexes) in which the NDI molecules interact both with the $\mathrm{Ag}^{+}$ions and with the $\mathrm{Zn}$-porphyrins (see representative structures in Figure 6). In addition, interactions among the three NDI molecules can be also observed (see Figure S12).

\section{Photoinduced processes within the inclusion complexes}

As revealed by spectrofluorimetric titration experiments, formation of the complexes NDI@ $\left[\mathrm{Ag}_{4}(\mathbf{1})\right]^{4+}$ and NDI@[ $\left.\mathrm{Ag}_{4}(\mathbf{2})\right]^{4+}$ causes a quenching of the fluorescence of the $\left[\operatorname{Ag}_{4}(1)\right]^{4+}$ and $\left[\mathrm{Ag}_{4}(2)\right]^{4+}$ cages. This quenching can be ascribed to a fast pho- toinduced process occurring between the units of the host and the included guest, depopulating the porphyrins singlet excited states. An energy transfer process from the cage porphyrin to the guest can be excluded from thermodynamic reasons. Indeed, the lowest singlet excited state of NDI is higher in energy than the cage $\mathrm{Zn}$-porphyrin singlet excited state (an energy value of $3.20 \mathrm{eV}$ for ${ }^{1} \mathrm{NDI}$ can be derived from the maximum of fluorescence emission, Figure $\mathrm{S} 1$, and the value of $2.06 \mathrm{eV}$ for ${ }^{1}\left[\mathrm{Ag}_{4}(\mathbf{1})\right]^{4+}$ and ${ }^{1}\left[\mathrm{Ag}_{4}(\mathbf{2})\right]^{4+}$ has been previously reported $\left.{ }^{[15]}\right)$. Conversely, a LUMO-LUMO electron-transfer leading to a charge-separated (CS) state with a $\mathrm{Zn}$-porphyrin radical cation and a NDI radical anion is a feasible process. By considering a reported $\mathrm{Zn}$-porphyrin oxidation potential of $+0.70 \mathrm{~V}$ versus SCE in $\mathrm{CH}_{2} \mathrm{Cl}_{2}{ }^{[26]}$ and a NDI reduction potential of $-0.65 \mathrm{~V}$ in the same solvent (converted from $-1.10 \mathrm{~V}$ vs. Fc/ $\left.\mathrm{Fc}^{+[16 \mathrm{~d}, 27]}\right)$, in fact, the energy of the CS state can be approximatively estimated at $1.4 \mathrm{eV}$, thus thermodynamically accessible from the cage $\mathrm{Zn}$-porphyrin singlet excited state. Moreover, the process is strongly favoured by the close proximity of the porphyrin planes and the NDI $\pi$ system in the fixed sandwich geometry of the complexes ( $d_{\text {porphyrin-NDI }} \leq 0.4 \mathrm{~nm}$, from MD simulations).

In order to gain better insights into the photophysics of the systems, pump-probe transient absorption experiments with femtosecond resolution were performed. Higher concentration conditions were used to provide an appropriate absorbance of the solutions at $560 \mathrm{~nm}$, the excitation wavelength chosen to selectively populate the $\mathrm{Zn}$-porphyrin singlet and to avoid photodegradation of the silver(I)-cages. Solutions of cages 1 and $2, \mathrm{ca} .6 \times 10^{-6} \mathrm{M}$, have been treated with $\mathrm{Ag}(\mathrm{OTf})$ to obtain

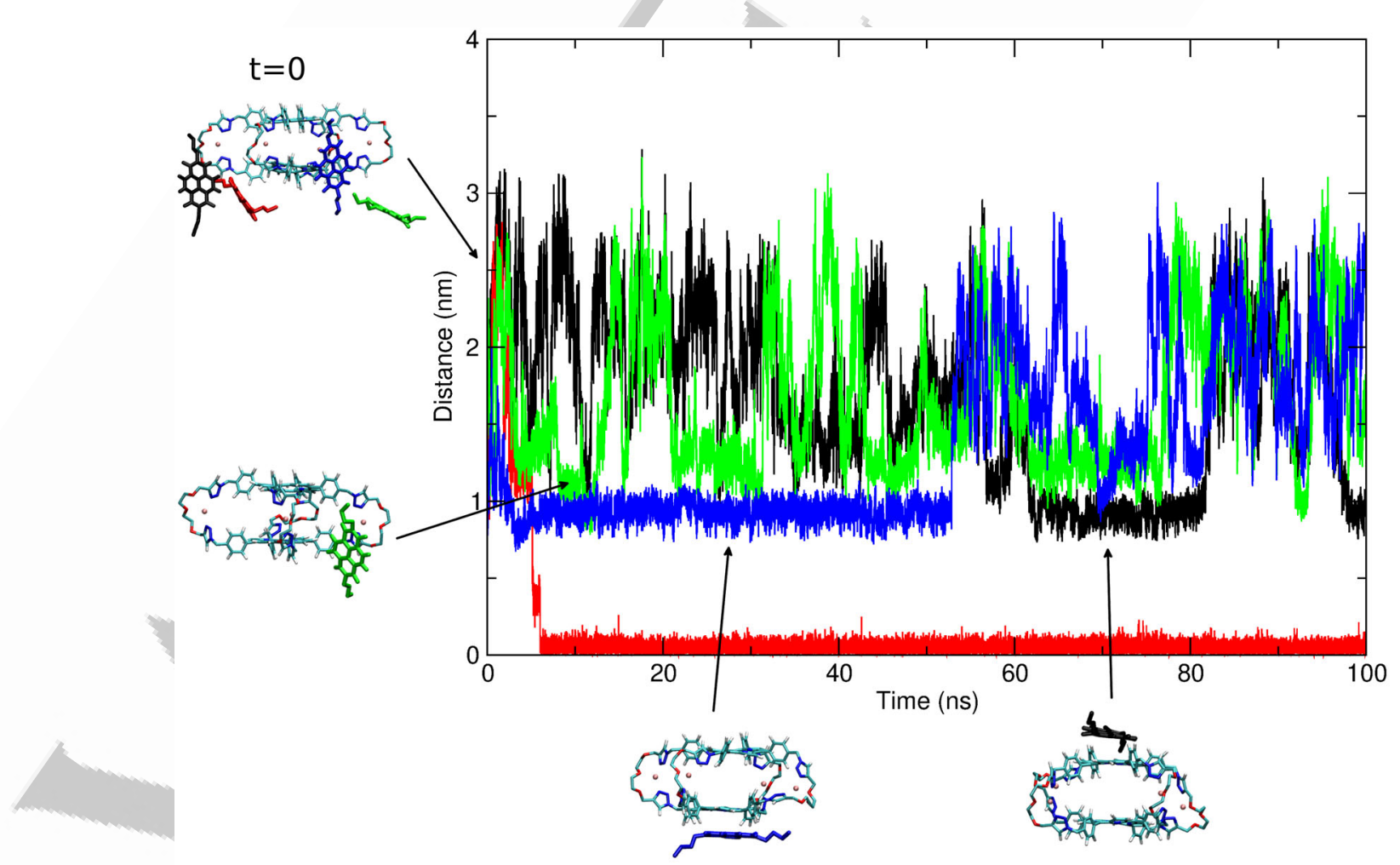

Figure 6. Time evolution of the distance between the center of mass of each NDI molecule and the center of mass of the two Zn-porphyrins. Representative structures of the relative position of the NDI molecules and the $\left[\mathrm{Ag}_{4}(\mathbf{2})\right]^{4+}$ cage are reported. 
the open conformation and then added with NDI to have a sizeable amount of complex in solution (50\% of complexed cage). NDI concentrations of $2.1 \times 10^{-3} \mathrm{M}$ and $3.6 \times 10^{-3} \mathrm{M}$ were used for $\left[\mathrm{Ag}_{4}(1)\right]^{4+}$ and $\left[\mathrm{Ag}_{4}(2)\right]^{4+}$, respectively. Absorption and emission spectra of the mixtures, compared with those of the open cages, are reported in Figures S13 and S14; it can be seen that the trend in the decrease of the Soret band upon complexation with NDI is confirmed, accompanied by a slight red-shift of the same band and the formation of a shoulder at ca. $430 \mathrm{~nm}$. The ca. $50 \%$ quenching measured for the porphyrin fluorescence in the mixtures attested the amount of formed complex.

Transient absorption measurements were performed on the host-guest mixtures and on solutions of bare cages and of silver(I)-complexed cages, at the same concentrations, for comparison purposes. Figure 7 shows the time evolution of the transient absorption spectra of $1,\left[\mathrm{Ag}_{4}(1)\right]^{4+}$ and the mixture containing NDI@[ $\left[\mathrm{Ag}_{4}(\mathbf{1})\right]^{4+}$, upon excitation at $560 \mathrm{~nm}$. In cage 1 , the end-of-pulse spectrum presents a positive signal with maximum at ca. $470 \mathrm{~nm}$ superimposed with the ground state bleaching of the Q-bands, at 560 and $600 \mathrm{~nm}$, and stimulated emission at 606 and $660 \mathrm{~nm}$. These absorption features, typical of a Zn-porphyrin singlet excited state, evolve towards a spectrum with maximum at $476 \mathrm{~nm}$, that can be safely attributed to triplet absorption. A clear isosbestic point at $504 \mathrm{~nm}$ and the lifetime of $1.7 \mathrm{~ns}$ found for signals decays and growths (see Figure S15A for the kinetic analysis at representative wavelengths) leads to identify the process as $\mathrm{S} 1 \rightarrow \mathrm{T} 1$ intersystem crossing. In the silver(I)-complexed cage, the picture is very similar, except for a prompt decay (13 ps, pre-exponential weight $\leq 20 \%$ ) of the singlet signal that precedes the intersystem crossing evolution (Figure S15B). This fast event can be ascribed to static quenching between the porphyrin units forced to stay in a face-to-face conformation in the $\mathrm{Ag}^{\prime}$-complexed cage or to a specific interaction with the $\mathrm{Ag}^{+}$ions. ${ }^{[28]}$ The picture for the mixture containing NDI@ $\left[\mathrm{Ag}_{4}(\mathbf{1})\right]^{4+}$ is markedly different (Figure $7 \mathrm{C}$ ). A signal rise of $1.5 \mathrm{ps}$ is observed in the range $470-650 \mathrm{~nm}$, then the transient spectrum decays with a lifetime of ca. $30 \mathrm{ps}$ and, on longer time scales, a kinetics of $1700 \mathrm{ps}$ for the decay of the singlet signal and rise of the triplet spectrum, is detected (Figure S15C). Although weak, the spectral features of the species that forms in $1.5 \mathrm{ps}$ and decays in $30 \mathrm{ps}$ can be safely assigned to the CS state $\mathrm{P}^{+}-\mathrm{NDI}^{-}$(with $\mathrm{P}$ : cage porphyrin). In fact, the $\mathrm{Zn}$-porphyrin cation is known to have a broad absorption between 600 and $700 \mathrm{~nm}^{[29]}$ whereas the NDI radical anion has characteristic absorption bands at ca. 475 (most intense), 610, 680 and $760 \mathrm{~nm}^{[16 c, 30]}$ It can be noticed that the amount of formed triplet is approximatively half that observed for the $\left[\mathrm{Ag}_{4}(1)\right]^{4+}$ solution, indicating that the NDI-free cages undergo the normal intersystem crossing path, whereas the ones complexed with NDI experience fast charge separation followed by charge recombination to the ground state.

The same analysis has been performed for $2,\left[\mathrm{Ag}_{4}(2)\right](\mathrm{OTf})_{4}$ and the mixture containing $\mathrm{NDI}\left[\mathrm{Ag}_{4}(2)\right](\mathrm{OTf})_{4}$; the results are presented in Figures S16 and S17. Features similar to the previous case are observed for the transient absorption evolution of
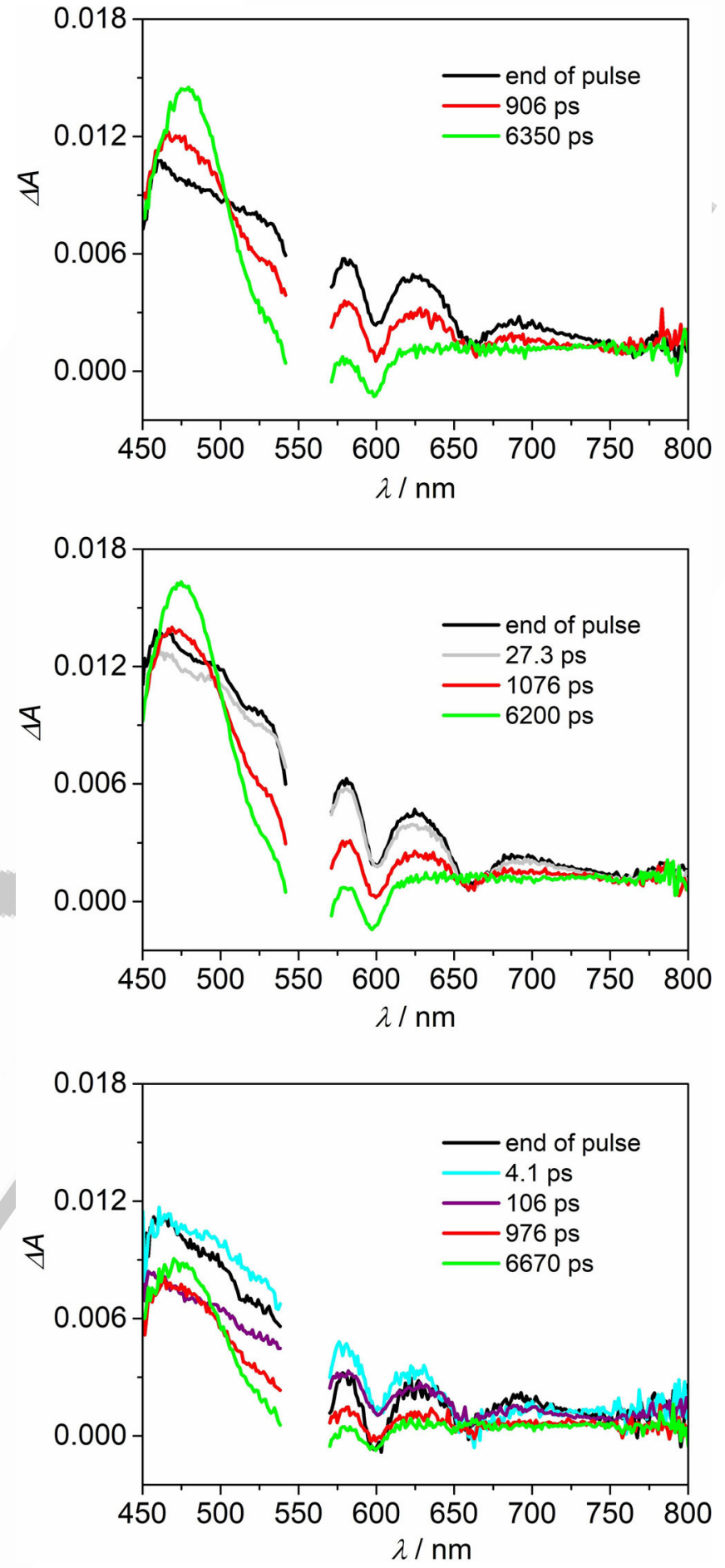

Figure 7. Time evolution of the transient absorbance of $\mathrm{CH}_{2} \mathrm{Cl}_{2} / \mathrm{MeOH}(9: 1)$ solutions of A) cage $1\left(5.8 \times 10^{-6} \mathrm{M}\right)$, B) cage $\left[\mathrm{Ag}_{4}(1)\right]^{4+}\left(5.8 \times 10^{-6} \mathrm{M}\right)$ and C) mixture of the latter with NDI $2.1 \times 10^{-3} \mathrm{M}$; excitation at $560 \mathrm{~nm}$ $\left(A_{560}=0.050,0.2 \mathrm{~cm}\right.$ optical path). The spectral region around $560 \mathrm{~nm}$ is covered by scattering of the excitation beam.

2 and its silver(I)-complex (Figure S16A and B): intersystem crossing occurs with a time constant of $1.6 \mathrm{~ns}$ in 2 , and this process is preceded by a fast decay of ca. 4 ps for $\left[\mathrm{Ag}_{4}(2)\right]^{4+}$ (Figure S17 A and B). In the mixture, at a difference with the previous case, the rise of the absorption bands of the radicals 
is not observed, and the end-of-pulse spectrum already contains weak CS features superimposed with the singlet absorption of the guest-free cage (Figure S16C). This implies that charge separation occurs within the time resolution of the system, that is, $300 \mathrm{fs}$. This spectrum then evolves with a decay of $38 \mathrm{ps}$ and, on longer time scales, the triplet features appear as a result of triplet population in the free cages present in solution (Figures S16C and S17C).

Overall the data indicate that a photoinduced host-guest electron transfer process occurs in both complexes upon excitation of the porphyrin components on fast and ultrafast scales $\quad\left(1.5 \mathrm{ps}\right.$ and $\leq 300 \mathrm{fs}$ for $\mathrm{NDI} @\left[\mathrm{Ag}_{4}(1)\right]^{4+}$ and $\mathrm{NDI} @\left[\mathrm{Ag}_{4}(2)\right]^{4+}$, respectively). The faster rate for the latter is likely due to the shorter distance between the $\mathrm{Zn}$-porphyrin and NDI, allowed by the longer flexible linkers of cage $2 .^{[15]}$ Charge recombination occurs with a similar kinetics in the two systems, with lifetime of the CS state of ca. 30-40 ps (an energy level diagram and the observed rate constants are reported in Scheme 1). These values reflect the high efficiency of both processes, likely due to the very short distance between donor and acceptor units in the formed inclusion complexes, as evidenced by the MD simulation and in accordance with Marcus electron transfer theory. ${ }^{[31]}$

\section{Conclusions}

A thorough study of the encapsulation of NDI in Zn-porphyrin molecular cages endowed with triazoles-including connectors of different lengths have been performed by means of absorption and emission spectroscopies and molecular dynamics sim-

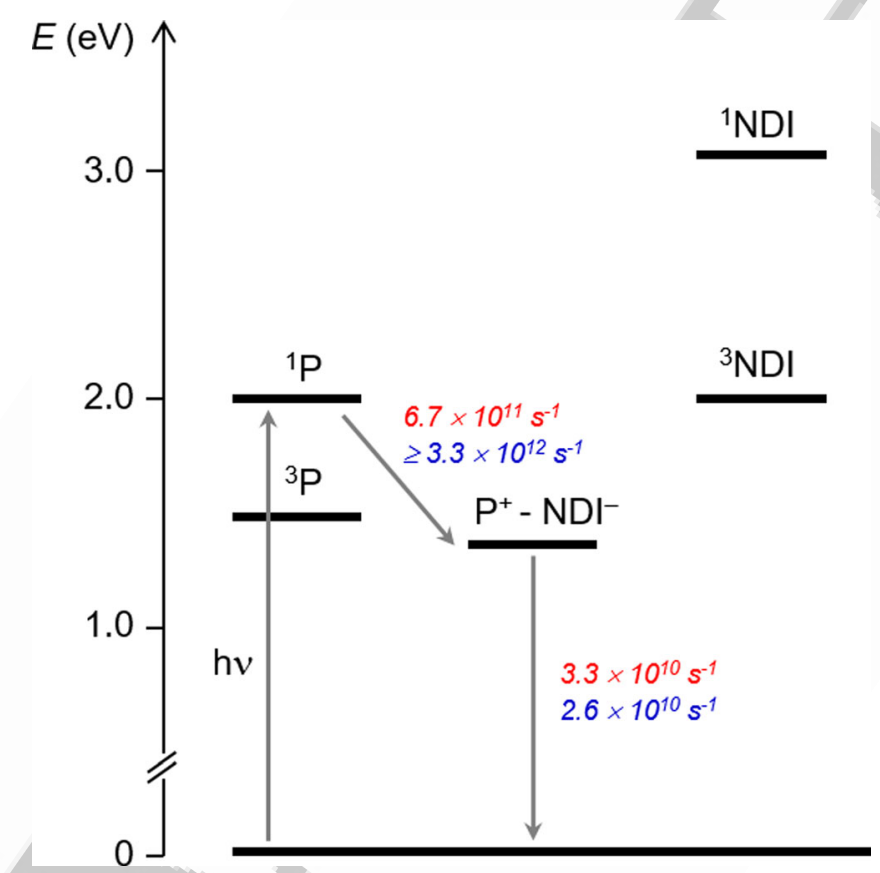

Scheme 1. Energy level diagram and derived kinetics of the photoinduced processes in the inclusion complexes NDI@ $\left[\operatorname{Ag}_{4}(\mathbf{1})\right]^{4+}$ (red) and $\mathrm{NDI} @\left[\mathrm{Ag}_{4}(2)\right]^{4+}$ (blue). P stands for cage porphyrin. The singlet and triplet energy levels are taken from data of the present paper and from literature. ${ }^{[15,32]}$ ulations. Whereas the photophysical properties of the cages are overall not affected by the presence a large excess of NDI, addition of silver(I) ions triggers NDI encapsulation and a strong quenching of the cage Zn-porphyrin emission. Molecular dynamics simulation shows that the stable host-guest complex forms within a few nanoseconds, probably mediated by favorable cation $-\pi$ interactions between the $\mathrm{Ag}^{\prime}$ ions and NDI molecules. Silver(I) binding controls the overall disposition of the $\mathrm{Zn}$-porphyrins in the cages in a face to face geometry that finely adjust upon NDI encapsulation to optimize the $\pi$ donor$\pi$ acceptor interactions, as shown by the simulation. In these Ag'-triggered NDI inclusion complexes a photoinduced electron transfer process thus occurs with almost unitary efficiency from the excited $\mathrm{Zn}$-porphyrin components to NDI, in $1.5 \mathrm{ps}$ for NDI@[Ag $\left.g_{4}(1)\right](O T f)_{4}$ and ultrafast scales $(\leq 300 \mathrm{fs})$ for $\mathrm{NDI} @\left[\mathrm{Ag}_{4}(2)\right](\mathrm{OTf})_{4}$. Following charge separation, charge recombination between the oxidized $\mathrm{Zn}$-porphyrin and the reduced NDI in both inclusion complexes occurs in tens of picoseconds. The present study demonstrates the $\mathrm{Ag}^{\prime}$ ions allosteric control on the encapsulation of the guest and, consequently, on the host-guest photoinduced electron transfer and on the photophysical properties of the cages. Such control opens the way to develop fine-tuned sensors, signaling receptors or photoreactors.

\section{Experimental Section}

Absorption and emission spectroscopy: Spectroscopic grade solvents from Merck were used as received. Silver trifluoromethanesulfonate (Ag(OTf)), from Sigma-Aldrich, was stored under argon in a sealed vial in dark and dry conditions. Freshly prepared $\mathrm{Ag}$ (OTf) solutions were always used. Solutions of cage $\mathbf{2}$ were filtered with $0.2 \mu \mathrm{m}$ membrane filters (Minisart RC4 filters) prior to each measurement, to avoid aggregation issues.

Absorption and emission spectra were recorded with a PerkinElmer Lambda 650 spectrophotometer and a Edinburgh FLS920 fluorimeter, equipped with a Peltier-cooled Hamamatsu R928 PMT (280$850 \mathrm{~nm})$, respectively. The reported emission spectra are un-corrected for the phototube response. Titration experiments were performed by incremental addition of micro aliquots of stock solutions of NDI $\left(8 \times 10^{-4} \mathrm{M}^{-1} \times 10^{-3} \mathrm{M}\right)$ to a solution of silver(I)-complexed cage (ca. $\left.2 \times 10^{-7} \mathrm{M}\right)$. The final volume added was kept below $10 \%$ of the total volume, to avoid dilution of the porphyrin. The experiments have been conducted avoiding light exposure of the solutions.

Titration data have been analyzed with Reactlab Equilibria and Hypspec softwares and according to Equation (1), derived for a 1:1 host-guest stoichiometry:

$O b s=O b s_{0}+\left(\Delta O b s_{\max } / 2 S_{0}\right) \times\left\{K_{d}+X+S_{0}-\left[\left(K_{d}+X+S_{0}\right)^{2-} 4 X S_{0}\right]^{1 / 2}\right\}$

where $\mathrm{Obs}_{0}$ is the signal (absorbance or emission intensity) of the free $\left[\mathrm{Ag}_{4}(\mathbf{1})\right]^{4+}, \Delta \mathrm{Obs}\left(\mathrm{Obs}-\mathrm{Obs}_{0}\right)$ is the change in the optical signal with respect to that of the free $\left[\operatorname{Ag}_{4}(\mathbf{1})\right]^{4+}, S_{0}$ is the constant concentration of $\left[\operatorname{Ag}_{4}(1)\right]^{4+}, X$ is the variable concentration of NDI, $\Delta O b s_{\max }$ is the maximum variation of the observed signal between non-complexed and complexed states and $K_{d}=1 / K_{a}$ is the dissociation constant of the 1:1 complex. ${ }^{[10, k, 33]}$ 
Emission lifetimes were determined by using an IBH time-correlated single-photon counting apparatus with excitation at 560 for porphyrin cages and at $331 \mathrm{~nm}$ and $465 \mathrm{~nm}$ for NDI and NDI ${ }_{n}$, respectively.

Pump-probe transient absorption measurements were performed with an Ultrafast Systems HELIOS (HE-VIS-NIR) femtosecond transient absorption spectrometer by using, as excitation source, a Newport Spectra Physics Solstice-F-1K-230 V laser system, ${ }^{[34]}$ combined with a TOPAS Prime (TPR-TOPAS-F) optical parametric amplifier (pulse width: $100 \mathrm{fs}, 1 \mathrm{kHz}$ repetition rate, selected output wavelength: $560 \mathrm{~nm}$ ). The overall time resolution of the system is $300 \mathrm{fs}$. Air-equilibrated solutions in $0.2 \mathrm{~cm}$ optical path cells were analyzed under continuous stirring. To reduce photo-degradation, the pump energy on the sample was reduced to $2 \mu \mathrm{J} /$ pulse. Surface Xplorer V4 software from Ultrafast Systems was used for data acquisition and analysis. The 3D data surfaces were corrected for the chirp of the probe pulse prior to analysis.

Estimated errors are $10 \%$ on transient absorbance lifetimes, $10 \%$ for luminescence lifetimes, $10 \%$ for molar absorption coefficients and $10 \%$ on quantum yields. The reductions in emission intensity and lifetime observed for the "closed" cages treated with NDI can be considered reliable even if they fall within instrumental errors, due to the maintenance of the same experimental conditions and to the consistency of the decrease determined with two different techniques.

Molecular dynamics simulations: MD simulations of silver(l)-complexed cage $2,\left[\mathrm{Ag}_{4}(2)\right]^{4+}$, in the presence of $4 \mathrm{NDI}$ molecules are performed in $\mathrm{CH}_{2} \mathrm{Cl}_{2} / \mathrm{MeOH}$ (90:10) to mimic the experimental conditions at the end of the titrations with NDI, in which the number of equivalents of NDI is around 400. Despite the high number of equivalents, the experimental NDI concentration is very low ( $\approx 10^{-5}-10^{-6} \mathrm{M}$ ). Given the limited size of the simulation box (compared to what would be needed to reproduce the very low experimental concentration), to find a compromise between NDI concentration and number of equivalents and to avoid over-crowding of the simulation box, we had to drastically reduce the number of NDI molecules from around 400 to 4 . The initial structure of the silver(I)-complexed cage $\mathbf{2}$ was taken from a previous MD simulation in the same solvent. ${ }^{[15]}$

MD simulations are performed with the GROMACS software package using the GROMOS force field. The previously derived GROMOS force field parameters and atomic charges for the silver(I)-complexed cage 2 are used. ${ }^{[15]}$ The GROMOS force field parameters and atomic charges for the NDI molecules are obtained from the Automated Topology Builder (ATB). ${ }^{[35]}$

The silver(I)-complexed cage $\mathbf{2}$ and the four NDI molecules are placed in a dodecahedral box large enough to contain the molecule and at least $1.0 \mathrm{~nm}$ of solvent on all sides with a proper number of $\mathrm{CH}_{2} \mathrm{Cl}_{2}$ molecules to reproduce the density of $\mathrm{CH}_{2} \mathrm{Cl}_{2}$ at $300 \mathrm{~K}$ and 1 bar $\left(1.33 \mathrm{~g} \mathrm{~cm}^{-13}\right)$. A proper number of $\mathrm{CH}_{2} \mathrm{Cl}_{2}$ molecules was then substituted with the corresponding number of $\mathrm{MeOH}$ molecules to reproduce the experimental $\mathrm{CH}_{2} \mathrm{Cl}_{2} / \mathrm{MeOH}$ (90:10) proportion. The force field parameters for $\mathrm{CH}_{2} \mathrm{Cl}_{2}$ and $\mathrm{MeOH}$ are taken from the GROMACS topology database.

The initial structure of the silver(I)-complexed cage $\mathbf{2}$ is placed in the center of the box and two starting configurations for the four NDI molecules are chosen. In the first one, the four NDI molecules are placed below the cage cavity with randomly selected orientations between the NDI plane and the porphyrin planes and with distances between the center of mass of the NDI and the center of mass of the two $\mathrm{Zn}$ atoms varying from $\approx 1 \mathrm{~nm}$ to $\approx 2 \mathrm{~nm}$ (average distance $\approx 1.7 \mathrm{~nm}$, see Figure $3 \mathrm{~A}$ ). In the second starting configura- tion the NDI molecules are placed perpendicularly to the two porphyrin planes in-between the four linkers with an average distance between the center of mass of the NDI and the center of mass of the two $\mathrm{Zn}$ atoms of $\approx 1 \mathrm{~nm}$ (see Figure $3 \mathrm{~B}$ ).

Simulations are carried out in the NVT (i.e., with constant number of molecules, volume and temperature) ensemble at a constant temperature of $300 \mathrm{~K}$ using the velocity rescaling temperature coupling. ${ }^{[36]}$ The LINCS algorithm ${ }^{[37]}$ is used to constrain bond lengths and a time step of $2 \mathrm{fs}$ for numerical integration of the equations of motion is used. The particle mesh Ewald method ${ }^{[38]}$ is used for the calculation of the long-range interactions and a cut-off of $1.1 \mathrm{~nm}$ is used. After a solute optimization and a subsequent solvent relaxation, each system is gradually heated from 50 to $300 \mathrm{~K}$ using short MD simulations. The trajectories were then propagated for $100 \mathrm{~ns}$ for each system. Coordinates are saved at every $1 \mathrm{ps}$.

\section{Acknowledgements}

Italian CNR (Project "PHEEL") is acknowledged for funding. The Ministry of Education and Research is acknowledged for a Ph.D. fellowship to R.D. The International Center for Frontier Research in Chemistry, icFRC (www.icfrc.fr), and the LabEx-CSC are gratefully acknowledged for financial support. We also thank the ANR Agency for the funding of the project ANR 14CE06-0010 "Switchable cages".

\section{Conflict of interest}

The authors declare no conflict of interest.

Keywords: allosteric control · electron transfer - molecular container $\cdot$ molecular dynamics $\cdot$ porphyrin

[1] J. M. Lehn, Acc. Chem. Res. 1978, 11, 49-57.

[2] a) Y. R. Hristova, M. M. J. Smulders, J. K. Clegg, B. Breiner, J. R. Nitschke, Chem. Sci. 2011, 2, 638-641; b) P. Wei, X. Yan, F. Huang, Chem. Soc. Rev. 2015, 44, 815-832; c) A. Galan, P. Ballester, Chem. Soc. Rev. 2016, 45, $1720-1737$.

[3] a) S. Rieth, K. Hermann, B.-Y. Wang, J. D. Badjić, Chem. Soc. Rev. 2011, 40, 1609-1622; b) T. Y. Kim, R. A. S. Vasdev, D. Preston, J. D. Crowley, Chem. Eur. J. 2018, 24, 14878-14890.

[4] a) M. Liu, X. Yan, M. Hu, X. Chen, M. Zhang, B. Zheng, X. Hu, S. Shao, F. Huang, Org. Lett. 2010, 12, 2558-2561; b) R. S. Stoll, S. Hecht, Angew. Chem. Int. Ed. 2010, 49, 5054-5075; Angew. Chem. 2010, 122, $5176-$ 5200; c) O. B. Berryman, A. C. Sather, A. Lledó, J. Rebek Jr, Angew. Chem. Int. Ed. 2011, 50, 9400-9403; Angew. Chem. 2011, 123, 9572-9575; d) E. Busseron, J. Lux, M. Degardin, J. Rebek, Jr., Chem. Commun. 2013, 49, 4842-4844; e) M. Han, R. Michel, B. He, Y.-S. Chen, D. Stalke, M. John, G. H. Clever, Angew. Chem. Int. Ed. 2013, 52, 1319-1323; Angew. Chem. 2013, 125, 1358-1362; f) N. Kishi, M. Akita, M. Kamiya, S. Hayashi, H.-F. Hsu, M. Yoshizawa, J. Am. Chem. Soc. 2013, 135, 12976-12979; g) A. Díaz-Moscoso, F. A. Arroyave, P. Ballester, Chem. Commun. 2016, 52, $3046-3049$.

[5] a) S. Stojanović, D. A. Turner, A. I. Share, A. H. Flood, C. M. Hadad, J. D. Badjić, Chem. Commun. 2012, 48, 4429-4431; b) I. Pochorovski, F. Diederich, Acc. Chem. Res. 2014, 47, 2096-2105; c) V. Croué, S. Goeb, G. Szalóki, M. Allain, M. Sallé, Angew. Chem. Int. Ed. 2016, 55, 1746-1750; Angew. Chem. 2016, 128, 1778-1782.

[6] a) N. Branda, R. M. Grotzfeld, C. Valdes, J. Rebek, Jr., J. Am. Chem. Soc. 1995, 117, 85-88; b) S. Rieth, B.-Y. Wang, X. Bao, J. D. Badjić, Org. Lett 2009, 11, 2495-2498; c) N. Kishi, M. Akita, M. Yoshizawa, Angew. Chem. Int. Ed. 2014, 53, 3604-3607; Angew. Chem. 2014, 126, 3678-3681; d) J. Mendez-Arroyo, J. Barroso-Flores, A. M. Lifschitz, A. A. Sarjeant, C. L. 
Stern, C. A. Mirkin, J. Am. Chem. Soc. 2014, 136, 10340-10348; e) S. Löf fler, J. Lübben, L. Krause, D. Stalke, B. Dittrich, G. H. Clever, J. Am. Chem. Soc. 2015, 137, 1060-1063; f) D. Preston, A. Fox-Charles, W. K. C. Lo, J. D. Crowley, Chem. Commun. 2015, 51, 9042-9045.

[7] a) A. Peracchi, A. Mozzarelli, Biochim. Biophys. Acta Proteins Proteomics 2011, 1814, 922-933; b) P. Tompa, Chem. Rev. 2014, 114, 6715-6732.

[8] T. Cardona, A. Sedoud, N. Cox, A. W. Rutherford, Biochim. Biophys. Acta Bioenerg. 2012, 1817, 26-43.

[9] F. Müh, C. Glöckner, J. Hellmich, A. Zouni, Biochim. Biophys. Acta Bioen erg. 2012, 1817, 44-65.

[10] a) Y. Kuroda, M. Ito, T. Sera, H. Ogoshi, J. Am. Chem. Soc. 1993, 115, 7003-7004; b) L. Flamigni, M. R. Johnston, New J. Chem. 2001, 25 $1368-1370$; c) L. Flamigni, A. M. Talarico, B. Ventura, J. Porphyrins Phthalocyanines 2003, 07, 318-327; d) S. Yagi, M. Ezoe, I. Yonekura, T. Takagishi, H. Nakazumi, J. Am. Chem. Soc. 2003, 125, 4068-4069; e) M. Tanaka, K. Ohkubo, C. P. Gros, R. Guilard, S. Fukuzumi, J. Am. Chem. Soc 2006, 128, 14625-14633; f) P. J. Thomassen, J. Foekema, R. Jordana i Lluch, P. Thordarson, J. A. A. W. Elemans, R. J. M. Nolte, A. E. Rowan, New J. Chem. 2006, 30, 148-155; g) S. Fukuzumi, Phys. Chem. Chem. Phys. 2008, 10, 2283-2297; h) H. Nobukuni, Y. Shimazaki, H. Uno, Y. Naruta, K Ohkubo, T. Kojima, S. Fukuzumi, S. Seki, H. Sakai, T. Hasobe, F. Tani, Chem. Eur. J. 2010, 16, 11611-11623; i) A. Takai, M. Chkounda, A. Eg genspiller, C. P. Gros, M. Lachkar, J.-M. Barbe, S. Fukuzumi, J. Am. Chem. Soc. 2010, 132, 4477-4489; j) A. Takai, C. P. Gros, J.-M. Barbe, S. Fukuzumi, Phys. Chem. Chem. Phys. 2010, 12, 12160-12168; k) L. P. HernándezEguía, E. C. Escudero-Adán, I. C. Pintre, B. Ventura, L. Flamigni, P. Ballester, Chem. Eur. J. 2011, 17, 14564; I) T. Kamimura, K. Ohkubo, Y. Kawashima, H. Nobukuni, Y. Naruta, F. Tani, S. Fukuzumi, Chem. Sci. 2013, 4 1451-1461; m) R. M. K. Calderon, J. Valero, B. Grimm, J. de Mendoza, D. M. Guldi, J. Am. Chem. Soc. 2014, 136, 11436-11443; n) S. Durot, J. Taesch, V. Heitz, Chem. Rev. 2014, 114, 8542-8578; o) T. Kamimura, K Ohkubo, Y. Kawashima, S. Ozako, K.-i. Sakaguchi, S. Fukuzumi, F. Tani, J. Phys. Chem. C 2015, 119, 25634-25650; p) P. Mondal, S. P. Rath, Chem. Eur. J. 2016, 22, 5607-5619; q) Y. Chiba, M. Liu, Y. Tachibana, T. Fujihara, Y. Tsuji, J. Terao, Chem. Asian J. 2017, 12, 1900-1904; r) P. Mondal, S. Banerjee, S. P. Rath, Eur. J. Inorg. Chem. 2019, 3629-3637.

[11] a) M. Linke, J.-C. Chambron, V. Heitz, J.-P. Sauvage, S. Encinas, F. Barigelletti, L. Flamigni, J. Am. Chem. Soc. 2000, 122, 11834-11844; b) M. Andersson, M. Linke, J.-C. Chambron, J. Davidsson, V. Heitz, L. Hammarström, J.-P. Sauvage, J. Am. Chem. Soc. 2002, 124, 4347-4362; c) L. Flamigni, A. M. Talarico, S. Serroni, F. Puntoriero, M. J. Gunter, M. R. Johnston, T. P. Jeynes, Chem. Eur. J. 2003, 9, 2649-2659; d) N. Watanabe, N. Kihara, Y. Furusho, T. Takata, Y. Araki, O. Ito, Angew. Chem. Int. Ed. 2003 42, 681-683; Angew. Chem. 2003, 115, 705-707; e) M. J. Gunter, Eur. J. Org. Chem. 2004, 1655-1673; f) K. Li, P. J. Bracher, D. M. Guldi, M. Á Herranz, L. Echegoyen, D. I. Schuster, J. Am. Chem. Soc. 2004, 126, 9156-9157; g) L. Flamigni, V. Heitz, J.-P. Sauvage, Porphyrin Rotaxanes and Catenanes: Copper(I)-Templated Synthesis and PhotoinducedProcess es, Vol. 121, Ed. E. Alessio, Springer, Berlin, Heidelberg, 2006, pp. 217 261 ; h) B. Ventura, L. Flamigni, M. Beyler, V. Heitz, J.-P. Sauvage, Chem Eur. J. 2010, 16, 8748-8756; i) J. D. Megiatto, D. I. Schuster, G. de Miguel, S. Wolfrum, D. M. Guldi, Chem. Mater. 2012, 24, 2472-2485; j) S. V. Kirner, C. Henkel, D. M. Guldi, J. D. Megiatto Jr, D. I. Schuster, Chem. Sci. 2015, 6, 7293-7304; k) M. Wolf, A. Ogawa, M. Bechtold, M. Vonesch, J. A. Wytko, K. Oohora, S. Campidelli, T. Hayashi, D. M. Guldi, J. Weiss, Chem. Sci. 2019, 10, 3846-3853.

[12] a) T. Hasobe, H. Imahori, P. V. Kamat, S. Fukuzumi, J. Am. Chem. Soc. 2003, 125, 14962-14963; b) K. Saito, V. Troiani, H. Qiu, N. Solladié, T. Sakata, H. Mori, M. Ohama, S. Fukuzumi, J. Phys. Chem. C 2007, 111, $1194-1199$; c) L. de Juan-Fernández, P. W. Münich, A. Puthiyedath, B. Nieto-Ortega, S. Casado, L. Ruiz-González, E. M. Pérez, D. M. Guldi, Chem. Sci. 2018, 9, 6779-6784.

[13] a) Z. Merican, K. D. Johnstone, M. J. Gunter, Org. Biomol. Chem. 2008, 6, 2534-2543; b) P. Spenst, F. Würthner, J. Photochem. Photobiol. C 2017, 31, 114-138; c) A. W. H. Ng, H. Y. Au-Yeung, Chem. Asian J. 2019, 14, $1602-1612$.

[14] R. Djemili, L. Kocher, S. Durot, A. Peuroren, K. Rissanen, V. Heitz, Chem. Eur. J. 2019, 25, 1481.
[15] L. Zanetti-Polzi, A. Amadei, R. Djemili, S. Durot, L. Schoepff, V. Heitz, B. Ventura, I. Daidone, J. Phys. Chem. C 2019, 123, 13094-13103.

[16] a) T. C. Barros, S. Brochsztain, V. G. Toscano, P. B. Filho, M. J. Politi, J. Photochem. Photobiol. A 1997, 111, 97-104; b) S. Alp, Ş. Erten, C. Karapire, B. Köz, A. O. Doroshenko, S. İçli, J. Photochem. Photobiol. A 2000, 135, $103-110$; c) L. Flamigni, E. Baranoff, J.-P. Collin, J.-P. Sauvage, Chem. Eur. J. 2006, 12,6592-6606; d) S. V. Bhosale, C. H. Jani, S. J. Langford, Chem Soc. Rev. 2008, 37, 331 -342; e) J. E. Bullock, M. T. Vagnini, C. Ramanan, D. T. Co, T. M. Wilson, J. W. Dicke, T. J. Marks, M. R. Wasielewski, J. Phys. Chem. B 2010, 114, 1794-1802.

[17] a) L. Flamigni, D. Wyrostek, R. Voloshchuk, D. T. Gryko, Phys. Chem. Chem. Phys. 2010, 12, 474-483; b) S. Maniam, H. F. Higginbotham T. D. M. Bell, S. J. Langford, Chem. Eur. J. 2019, 25, 7044-7057.

[18] M. Montalti, A. Credi, L. Prodi, M. T. Gandolfi, Rate Constants of ExcitedState Quenching, CRC Press, Taylor \& Francis Group, Boca Raton, 2006, p. 424.

[19] Ag(OTf) was added to the solution of the cage in a proportion similar or slightly higher than in previous titrations (ca. 20 equivalents) and the formation of the "open" conformation was monitored spectrophotometrically.

[20] ReactLabTM, E. 1.1, Jplus Consulting Pty Ltd.

[21] Hypspec in Vol. P. Gans, A. Sabatini, A. Vacca, Talanta 1996, 43, 1739 1753 (Protonics Software), http://www.hyperquad.co.uk/HypSpec.htm.

[22] M. S. Cubberley, B. L. Iverson, J. Am. Chem. Soc. 2001, 123, 7560-7563.

[23] C. R. Martinez, B. L. Iverson, Chem. Sci. 2012, 3, 2191-2201.

[24] S. Del Galdo, M. Aschi, A. Amadei, Int. J. Quantum Chem. 2016, 116, $1723-1730$

[25] C. A. Hunter, J. K. M. Sanders, J. Am. Chem. Soc. 1990, 112, 5525-5534.

[26] I. M. Dixon, J.-P. Collin, J.-P. Sauvage, L. Flamigni, Inorg. Chem. 2001, 40, 5507- 5517 .

[27] a) N. G. Connelly, W. E. Geiger, Chem. Rev. 1996, 96, 877-910; b) N. Sakai, J. Mareda, E. Vauthey, S. Matile, Chem. Commun. 2010, 46, 4225 4237.

[28] S. Durot, L. Flamigni, J. Taesch, T. T. Dang, V. Heitz, B. Ventura, Chem. Eur. J. 2014, 20, 9979.

[29] J. Fajer, D. C. Borg, A. Forman, D. Dolphin, R. H. Felton, J. Am. Chem. Soc. $1970,92,3451-3459$.

[30] a) D. Gosztola, M. P. Niemczyk, W. Svec, A. S. Lukas, M. R. Wasielewski, J. Phys. Chem. A 2000, 104, 6545-6551; b) G. Andric, J. F. Boas, A. M. Bond, G. D. Fallon, K. P. Ghiggino, C. F. Hogan, J. A. Hutchison, M. A. P. Lee, S. J. Langford, J. R. Pilbrow, G. J. Troup, C. P. Woodward, Aust. J. Chem. 2004, 57, 1011 -1019; c) M. Pan, X.-M. Lin, G.-B. Li, C.-Y. Su, Coord. Chem. Rev. 2011, 255, $1921-1936$.

[31] Photoinduced processes occurring within the assemblies upon excitation of the included NDI guest could not be studied due to a combination of experimental constraints: the low association constants, which require a large amount of one of the two partners with respect to the other to form a sizeable amount of complex in solution, the necessity to work in optical conditions and aggregation issues arising at high concentrations of NDI.

[32] S. Green, M. A. Fox, J. Phys. Chem. 1995, 99, 14752-14757.

[33] M. Beyler, V. Heitz, J.-P. Sauvage, B. Ventura, L. Flamigni, K. Rissanen, Inorg. Chem. 2009, 48, 8263-8270.

[34] A. Briš, P. Trošelj, D. Margetić, L. Flamigni, B. Ventura, ChemPlusChem 2016, 81, 985-994.

[35] A. K. Malde, L. Zuo, M. Breeze, M. Stroet, D. Poger, P. C. Nair, C. Oostenbrink, A. E. Mark, J. Chem. Theory Comput. 2011, 7, 4026.

[36] G. Bussi, D. Donadio, M. Parrinello, J. Chem. Phys. 2007, 126, 014101.

[37] B. Hess, H. Bekker, H. J. C. Berendsen, J. G. E. M. Fraaije, J. Comput. Chem. 1997, 18, 1463.

[38] T. Darden, D. York, L. Pedersen, J. Chem. Phys. 1993, 98, 10089.

Manuscript received: July 2, 2020

Revised manuscript received: August 24, 2020

Accepted manuscript online: August 26, 2020

Version of record online: $\mathbf{\square} \mathbf{\square}, 0000$ 


\section{FULL PAPER}

\section{Host-Guest Systems}

L. Zanetti-Polzi, R. Djemili, S. Durot,

V. Heitz, ${ }^{*}$ I. Daidone, ${ }^{*}$ B. Ventura*

口- $\mathbf{\square}$

Allosteric Control of Naphthalene Diimide Encapsulation and Electron Transfer in Porphyrin Containers: Photophysical Studies and Molecular Dynamics Simulation
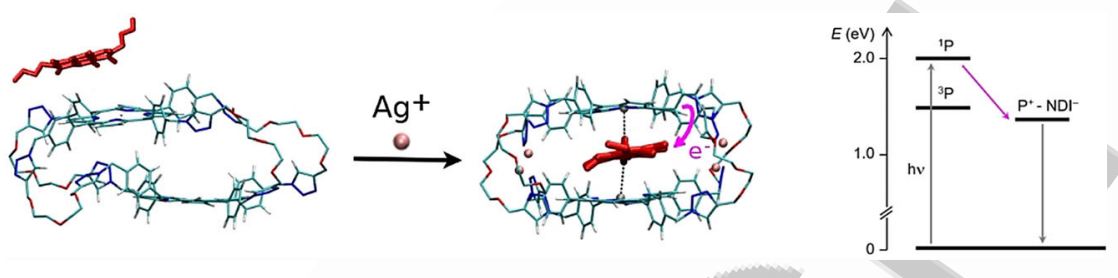

$\mathrm{Ag}^{+}$ions as chemical stimuli to control naphthalene diimide encapsulation and photoinduced electron transfer in porphyrin containers.

$y$

Allosteric control of naphthalene diimide encapsulation and electron transfer in porphyrin containers: photophysical studies and molecular dynamics simulation (Ventura, Heitz, Daidone) @b_ventura_@Heitz group SPACE RESERVED FOR IMAGE AND LINK

Share your work on social media! Chemistry - A European Journal has added Twitter as a means to promote your article. Twitter is an online microblogging service that enables its users to send and read text-based messages of up to 140 characters, known as "tweets". Please check the pre-written tweet in the galley proofs for accuracy. Should you or your institute have a Twitter account, please let us know the appropriate username (i.e., @accountname), and we will do our best to include this information in the tweet. This tweet will be posted to the journal's Twitter account @ChemEurJ (follow us!) upon online publication of your article, and we recommended you to repost ("retweet") it to alert other researchers about your publication.

Please check that the ORCID identifiers listed below are correct. We encourage all authors to provide an ORCID identifier for each coauthor. ORCID is a registry that provides researchers with a unique digital identifier. Some funding agencies recommend or even require the inclusion of ORCID IDs in all published articles, and authors should consult their funding agency guidelines for details. Registration is easy and free; for further information, see http://orcid.org/.

Laura Zanetti-Polzi http://orcid.org/0000-0002-2550-4796

Ryan Djemili

Stéphanie Durot http://orcid.org/0000-0001-8815-0422

Valérie Heitz http://orcid.org/0000-0002-5828-9199

Isabella Daidone http://orcid.org/0000-0001-8970-8408

Barbara Ventura http://orcid.org/0000-0002-8207-1659 